\title{
Condomínios horizontais fechados: reflexão sobre a configuração do espaço intrametropolitano de Goiânia
}

\author{
Genilda D'Arc Bernardes*e \\ Ademar Azevedo SoAres JÚNIOR**
}

\begin{abstract}
Resumo: O presente trabalho buscou evidenciar os impactos que os chamados condomínios horizontais fechados têm provocado na Região Metropolitana de Goiânia. Essa nova tipologia habitacional se mostra como marca evidente de um novo padrão de segregação socioespacial urbana, um processo social crescente de migração de parcelas significativas da população para bairros fechados, cercados por muros e sistemas de segurança sofisticados. O setor de habitação sempre exerceu importante papel na indução do adensamento e da expansão urbana dessa área, processo este que vem apresentando novas dinâmicas a partir da implantação dos condomínios fechados, contribuindo para a configuração de um novo espaço intrametropolitano de Goiânia.
\end{abstract}

Palavras-chave: condomínio horizontal fechado; Região Metropolitana de Goiânia; reestruturação socioespacial; desenho urbano; eixos de expansão.

A proposta deste texto consiste em compreender a formação do espaço urbano de Goiânia, cidade planejada nos anos 30 para ser a capital do estado de Goiás. Mais especificamente, é uma reflexão com base em três estudos, realizados junto ao programa de Mestrado em Sociologia da Universidade Federal de Goiás (UFG), ${ }^{1}$ que abordam as transformações na estrutura morfológica urbana derivadas dos impactos gerados pelos chamados condomínios horizontais fechados (CHFs), no espaço intrametropolitano de Goiânia.

Goiânia, desde a sua concepção, resulta de um projeto político marcado pela intervenção do Estado e representa hoje a efetiva modernização do Centro-Oeste. O mercado imobiliário, a partir

\footnotetext{
* Doutora em Sociologia, professora da UFG e coordenadora do Mestrado em Sociedade, Tecnologia e Meio Ambiente da UniEvangélica/Anápolis - GO. E-mail: genilda@hotmail.com.

** Mestre em Sociologia e professor da UFG e da UEG. Email: arquiteturjr@gmail.com.

1. Soares Junior (2005); Silva (2003); Macedo (2002).
}

da década de 1970, passa a constituir, ao lado do Estado, um agente de intervenção importante na formatação do espaço urbano da cidade. Com 1.093.007 habitantes (Censo/IBGE, 2000), Goiânia, apesar de jovem, a exemplo das metrópoles brasileiras, apresenta uma expansão urbana marcada por processos de auto-segregação urbana (CHFs), redes formadas por grandes equipamentos como shopping centers, hipermercados e crescentes bolsões de miséria que se localizam em seus bairros periféricos.

Essas formas de ocupação são típicas de processos segregatórios no contexto da cidade, sobretudo a partir dos anos 90 . A polarização social e a busca de segurança instauram nas médias e grandes cidades, em particular em Goiânia e em sua Região Metropolitana (RM), os chamados "condomínios fechados", assim como é crescente a tendência da auto-segregação nos bairros residenciais das classes médias e altas. Essa tendência se expressa por meio da expansão do mercado que comercializa vários 
sistemas sofisticados de segurança (grades, muros altos, cães adestrados e ferozes, cercas elétricas, circuito fechado de TV), além do pujante mercado imobiliário voltado para os possuidores de renda alta.

Ao mesmo tempo, a configuração da cidade reflete transformações próprias daquilo que os teóricos têm definido como cidade global, ou cidade na pós-modernidade (Sassen, 1998), ou seja, a concepção de que cidades e regiões resultam da ação de atores econômicos, políticos e sociais, nacionais e globais (Castells, 1992).

A cidade, na contemporaneidade, tem-se constituído objeto de reflexão, no tocante aos processos de globalização geradores de redes constituídas por grandes equipamentos como shopping centers, hipermercados e CHFs (Sassen, 1998). A reflexão sobre essa temática considera as mudanças históricas recentes ocorridas em nível global, que repercutem na configuração das metrópoles, com efeitos drásticos, principalmente, nas grandes cidades dos países em desenvolvimento.

Resguardando as especificidades das correntes de pensamento que interpretam o desenvolvimento histórico recente, parece haver um consenso de que, nos anos 60 e 70, ocorreram mudanças históricas, que modelaram as dimensões econômicas, políticas, sociais e culturais da sociedade mundial, com ênfase nos países do capitalismo central, como EUA e Europa ocidental. Porém, os impactos dessas mudanças atingem outras localidades como conseqüência dos processos de integração das sociedades contemporâneas, derivadas da globalização da economia, da criação das instituições supranacionais, da chamada sociedade informacional: acumulação flexível, sociedade pós-industrial (Touraine, 1994), pós- modernidade (Jameson, 1997), entre outros.

Como conseqüência desse processo, observam-se mudanças significativas no contexto das metrópoles, ao estabelecer novos sistemas de hierarquias urbanas mundiais e nacionais, resultando dele novas formas de organização espacial. São também observadas mudanças na configuração do Estado.

Segundo Harvey (1987), a explicação desses acontecimentos gravita em torno do processo de produção, que esquematicamente pode ser traduzido a partir do deslocamento do modelo fordista de produção baseado nas economias de escala (produção em massa de bens homogêneos, padronização, alto grau de especialização das tarefas desempenhadas pelo trabalhador, divisão espacial do trabalho, homogeneização do mercado de trabalho, fragmentação da classe trabalhadora, ampliação do setor de serviços; no tocante ao Estado: regulação, rigidez da negociação coletiva, socialização do bem-estar; no tocante à ideologia: sociedade de consumo; modernismo, mudanças a partir da totalidade e da estrutura) para uma configuração da acumulação flexível (declínio do Estado de Bem-Estar, motivada pela emergência no cenário internacional de novas economias representadas pelo Japão, pela Europa e por países recém-industrializados como o Brasil, que desafiam a economia norte-americana).

Para os objetivos deste estudo, nesse processo destacam-se o redimensionamento das formas de organização espacial e cultural. No primeiro, os impactos das transformações econômicas advindos da perda de importância das cidades industriais, devido à transferência dos investimentos para cidades menores ou para países em desenvolvimento, geram não apenas novos modelos de cidade, mas também criam uma massa de desempregados, que, quando não absorvidos pelo setor de serviços, passam a integrar o setor informal de trabalho ou engrossam os índices de desemprego. Uma vez marginalizados do setor produtivo, essa categoria ocupa os centros decadentes das grandes cidades ou habitam regiões periféricas, em situações de degradação humana e ambiental, passando a compor os chamados excluídos da cidade, ou os "condenados da cidade", na linguagem de Wacquant (2001).

No segundo, emergem traços característicos da chamada "pós-modernidade", por uns, ou da "sociedade pós-indústrial", por outros, como a pluralidade de discursos, pluralidade de espaços e temporalidades heterogêneas (a local, a étnica, a religiosa, a ideológica, a de gênero, $\mathrm{o}$ efêmero e o fragmentário)

Harvey (1987) reflete sobre o abandono dos "modelos de planejamento integrado modernista" dos anos 60, sobrepondo a esses formas de estratégias pluralistas e orgânicas, através das "cidades colagens" de espaços, nas quais a 
renovação urbana cede lugar aos chamados processos de revitalização.

A reestruturação econômica afeta a geografia política dos territórios, das cidades e das regiões, estabelecendo, principalmente, nos países em desenvolvimento uma convivência entre o urbanismo moderno e o pós-moderno, em uma espécie de bricolagem entre tradição, modernidade e pós-modernidade.

Nesses termos, a globalização estabelece "uma nova hierarquia de espaços, o aparecimento de novas funções desempenhadas em novos locais, e a reconfiguração física, econômica e social dos espaços existentes" (Levy, 1997). Nesse contexto, a "cidade global", ou as chamadas "cidades mundiais", funciona como sede do capital transnacional, abrigando nela centros financeiros, bancos e sedes administrativas. Essas cidades constituem espaços híbridos, ao abrigar as instituições políticas, econômicas e culturais já existentes e as novas configurações urbanas e espaciais. Por outro lado, assistimos a um crescimento vertiginoso das cidades metrópoles dos países emergentes. Modernas? Sim. Com os signos das estruturas urbanas pós-modernas? Sim. Porém, com graves problemas de desemprego, de pobreza urbana, de carência de infra-estrutura e com graves processos segregatórios.

A atuação do mercado globalizado, embora não o único, interfere nas dimensões do bairro, da família, da comunidade, "uma vez que constituem microestruturas, o elo capaz de unir a experiência individual e a ação coletiva à política urbana" (Smith e Tardanico, 1987, apud Levy, 1997).

A constatação de que a globalização gera uma nova hierarquia de espaços é relevante para a compreensão de Goiânia e região nesse processo. Pois, embora não possamos transferir de forma automática o conceito de cidade mundial, ou cidade global, para a compreensão das cidades dos países em desenvolvimento, Goiânia e região, ao mesmo tempo, se inserem na nova trama através da assunção de funções relacionada ao processo de reestruturação econômica, como consequiência da dispersão das empresas, dos lugares de trabalho, do declínio do modelo de cidades industriais tradicionais, da descentralização de empregos e da polinucleação de centros marcados pela presença de grandes equipamentos urbanos.

No caso de Goiânia, pesa ainda o fato de a região ter como função regional articular a exportação de produtos provenientes do agronegócio com o mercado internacional. Essa lógica ganha novos parâmetros, conforme Castells (1992), ao destacar a ascensão dos atores na economia internacional ao imporem uma lógica global, em detrimento das cidades e regiões.

Historicamente, no Brasil, verificamos nas décadas de 1950 e 1960, caracterizadas pelo período desenvolvimentista, o início de um processo mais intenso de urbanização nas cidades. Data desse período o começo da trajetória irreversível de metropolização de algumas cidades, conformando-se em grandes manchas urbanas, que se espalham além dos seus limites, de uma forma desordenada.

Além da crescente industrialização, acompanhada por um processo migratório intenso, muito contribuiu para esse panorama a especulação imobiliária, presente em várias cidades, fazendo com que a mancha urbana se expandisse de forma inédita no Brasil, proporcionando a valorização do solo urbano. Desses processos surgem os vazios urbanos, criando o distanciamento das áreas centrais, a periferização e o uso dos automóveis e ônibus como base da mobilidade urbana.

Diante dessa nova realidade urbana, percebe-se que o acesso às zonas mais bem assistidas, tanto em termos de infra-estrutura quanto de oferta de bens e serviços, passa a conferir valores diferentes às diversas localidades, sendo as áreas mais valorizadas habitadas pelas classes de mais alta renda. Estas, por sua vez, desempenham papel importante na estruturação desses espaços, uma vez que acabam por agregar valores a eles. A elite brasileira migra à procura de melhores locais para residência, de acordo com o crescimento da cidade. Regiões centrais e suas adjacências são privilegiadas. A classe média, por sua vez, passa a habitar as zonas verticalizadas de média e alta densidade, enquanto as classes baixas ocupam as franjas das cidades.

Dentro do setor de habitação, vamos ter, na década de 1970, a implantação de bairros previamente organizados e planejados, onde a forma de ocupação é conseqüência previsível 
de planos racionalmente traçados. Surgem os apartamentos racionais em série e é desse período também o aparecimento dos grandes condomínios verticais, comportando nos bairros mais centrais uma população composta por pessoas da classe média e média alta. Registra-se o início da implantação dos primeiros CHFs, com destaque para o surgimento do empreendimento Alphaville Barueri. ${ }^{2}$ Segundo Tramontano (1999), a concepção de condomínio surgiu nos EUA na década de 1950, quando os arredores das cidades foram invadidos por casas de campo. No Brasil, inicialmente, os condomínios surgiram ao redor da cidade de São Paulo, ocupando grandes glebas, ao longo das rodovias Castelo Branco e Raposo Tavares. "A Chácara Flora foi o primeiro loteamento fechado de São Paulo, executado antes mesmo de existir qualquer legislação municipal regulamentando este tipo de empreendimento"3 (Tramontano, 1999, p. 21).

De lá para cá, a urbanização brasileira temse caracterizado por um processo crescente de problemas acumulados no espaço de suas cidades: trânsito intenso e indisciplinado, poluição sonora, aumento da violência, decadência das áreas centrais, entre outros. Os males internos de algumas cidades agora se projetam em áreas mais amplas, chamadas regiões metropolitanas, gerando um ambiente urbano caótico e desumano. Os espaços dos condomínios horizontais fechados apresentam-se como contraponto perfeito a essa cidade desfigurada, pelo menos a uma parcela da população brasileira.

O mercado imobiliário soube se utilizar muito bem dessa situação. A fórmula que surge na década de 1970 cresce exponencialmente nos anos 90 em grande parte do território nacional. ${ }^{4}$ No entanto, não era só uma questão

\footnotetext{
2. O Alphaville constitui a experiência mais conhecida e de maior sucesso desse tipo de habitação no Brasil e está instalado hoje em várias cidades brasileiras, além de contar com uma unidade em Lisboa, Portugal. Esse modelo habitacional está assentado no tripé: casa própria-autoconstrução-loteamento periférico.

3. Hoje inúmeras cidades no país já têm legislação municipal que trata dessa forma de ocupação.

4. Nesse período, vamos verificar a reprodução dos condomínios horizontais fechados, extrapolando os limites geográficos das grandes cidades e se instalando em muitas cidades do interior do país.
}

de segurança, uma vez que o próprio condomínio vertical assegurava esse fator. Abria-se um mercado promissor, oferecendo, além da segurança, um espaço mais homogêneo, distante da malha urbana, relativamente funcional e com muita área verde. Além disso, o condomínio fechado acena como um elemento novo de diferenciação e distinção, demarcando distanciamentos com os não-iguais.

Temos hoje, no Brasil, uma realidade urbana consideravelmente demarcada por loteamentos fechados, localizados, em sua absoluta maioria, nos subúrbios das cidades, acessíveis por uma malha rodoviária de fluxo rápido. $\mathrm{O}$ espaço do condomínio fechado está muito ligado ao uso intenso do automóvel, como também ao modelo norte-americano da moradia no subúrbio.

Os condomínios fechados, em si, não são uma novidade completa, haja vista as experiências verificadas nas décadas de 1970 e 1980 . O que desperta a atenção, dos anos 90 até os dias de hoje, é o aumento do seu número e sua disseminação pelo país. Alguns condomínios, inclusive, estão sendo instalados em cidades que apresentam índices baixos de violência, se comparados às grandes cidades brasileiras. Além disso, temos um processo de popularização dessa fórmula, hoje oferecida para parcelas de menor poder aquisitivo. Essa rápida disseminação situa-se em um cenário mais amplo de modificações na esfera urbana e tem fomentado processos de reestruturação do espaço das cidades, que comportam tais condomínios.

A metrópole goiana constitui-se hoje na terceira capital do país em número de condomínios. É interessante verificar, em Goiânia, uma cidade de médio porte, a proliferação desses espaços. Segundo dados da Secretaria de Planejamento Municipal (Seplam), de 1995 para cá, cerca de $14 \mathrm{CHFs}^{5}$ foram implantados. Isto demonstra modificações na arquitetura da habi-

\footnotetext{
5. A Secretaria de Planejamento Municipal de Goiânia faz uma diferenciação entre condomínios horizontais fechados e conjuntos de habitações seriadas, apesar de os dois serem horizontais, cercados e com sistema de segurança próprio. $\mathrm{O}$ primeiro se caracteriza por ocupar grandes glebas com parcelas ideais, em geral acima de $500 \mathrm{~m}^{2}$, chegando até a $12.000 \mathrm{~m}^{2}$ e caracterizando-se por construções de alto poder aquisitivo; o segundo são como vilas, apropriando-se do conceito de segurança dos primeiros, ou seja, pequenas
} 
tação em Goiânia, indicando mudanças na sua vida urbana.

Em termos descritivos, devemos entender o condomínio horizontal fechado como:

[...] conjuntos de habitações cercados por muros, com entrada única, geralmente controlada por dispositivos como guarita. São conjuntos, como sugere a denominação, não verticalizados, nos quais as unidades habitacionais possuem acessos independentes e geralmente estão dispostas em lotes definidos. Constituem uma modalidade de ocupação do solo na qual verificam-se vários tipos de agrupamentos, das unidades habitacionais, desde unidades isoladas até blocos de unidades térreas, de dois pavimentos ou sobrepostos, passando por unidades geminadas por um só lado, podendo ser térreas ou de dois pavimentos. (Tramontano, 1999, p. 1)

Sem dúvida, o elemento mais emblemático dos condomínios é o muro, que acaba por estabelecer uma ruptura, seja ela física ou mesmo simbólica, diante do aglomerado maior da cidade. Conjunto de habitações horizontais, isolado em um sítio urbano comum, caracterizase principalmente pelo seu caráter privado e pelo espaço relativamente autônomo e funcional em relação à cidade. "Uma espécie de versão burguesa das conhecidas comunas socialistas segundo uns, um gueto ao contrário, para outros" (Almada, 1998, p. 40).

Na Região Metropolitana de Goiânia, contabilizamos um total de 19 condomínios, com as características próprias dessa tipologia: o tripé - casa própria, autoconstrução e loteamento periférico -, sendo que, destes, 14 estão implantados na cidade de Goiânia, dois no município de Aparecida de Goiânia, dois no município de Goianira e um no município de Santo Antônio de Goiás. São eles: Privê Atlântico (1978), Jardins Viena (1995), Jardins Florença (1997), Aldeia do Vale (1997), Residencial Granville (1998), Jardins Madri (2000), Jardins Mônaco (2000), Portal do Sol I (2001), Complexo

parcelas com construções padronizadas e cercadas. Para efeito deste estudo, o número de condomínios se amplia, uma vez que adotaremos o conceito de CHFs e consideraremos também as unidades residenciais seriadas de grande porte, sendo os principais em número de cinco.
Alphaville Flamboyant ${ }^{6}-3$ etapas: Residencial Cruzeiro do Sul, Residencial Goiás e Residencial dos Ipês (2001), Portal do Sol II (2002), Jardins Paris (2003), Jardins Atenas (2003), Residencial Califórnia (2004), Residencial Araguaia (2004), Goiânia Golfe Residence (2005), Jardins Milão (2005), Recanto das Águas Condomínio Fechado (2005), Villaggio Baiocchi Condomínio Horizontal (2005) e Condomínio do Lago (2005). Como estamos trabalhando também com conjuntos residenciais classificados pela Seplam, como habitações seriadas, este número se amplia para 24, se somados aos condomínios horizontais fechados propriamente ditos. É preciso ressaltar que, para nosso estudo, foram selecionados os conjuntos residenciais seriados de maior porte. São eles: Privê dos Girassóis (1999), Housing Alphaville Flamboyant (2001), Residencial Monte Verde (2001), Fontana Di Trevi (2001) e Condomínio Alto da Boa Vista (2004).

Os condomínios horizontais fechados constituem espaços eminentemente residenciais, apesar de a maioria deles agregarem a seus projetos outras funções. Sua função básica é a de moradia; nesse sentido, o condomínio, ao mesmo tempo em que amplia a diversidade de tipologias habitacionais na cidade, reestrutura significativamente seu espaço urbano, refazendo a "periferia da cidade, sua identidade, seu teor de classe e seus símbolos [...], emoldurando novas paisagens na metrópole goianiense" (Almeida, 2004, p. 55).

O primeiro condomínio fechado de Goiânia foi implantado no final da década de 1970. O Privê Atlântico nasceu primeiro como conjunto habitacional, voltado para classe média, financiado pelo BNH e formado por casas pré-construídas e lotes para posterior construção. Só na década de 1990 que o conjunto vai receber status de condomínio fechado pelo poder público.

6. São denominadas complexo Alphaville Flamboyant as três primeiras etapas desse empreendimento, que têm características diferenciadas em relação às etapas dos demais condomínios, pois cada uma conta com cercamento e guarita individualizada, dando a impressão de três condomínios em uma única área. Já os outros empreendimentos da Flamboyant Urbanismo, o Housing Alphaville Flamboyant e o Residencial Araguaia, foram contabilizados à parte desse complexo, uma vez que o primeiro é classificado como conjunto residencial seriado e o segundo está em processo de implantação, não tendo, portanto, residentes. 
Todos os outros condomínios de grande porte vão ser implantados a partir da metade da década de 1990 para cá, configurando-se como ícones da paisagem urbana da Grande Goiânia atualmente.

No Brasil, ainda não temos uma legislação federal que versa sobre a tipologia habitacional condomínio horizontal fechado. A Lei n ${ }^{\circ} 6.766$, de dezembro de 1979, regula o parcelamento do solo urbano ${ }^{7}$ em todo território nacional, permitindo que o estado e os municípios estabeleçam sua normatização. ${ }^{8}$ Em 1991, foi promulgada em Goiânia a Lei de n ${ }^{\circ} 7.042$, que dispõe sobre a aprovação de planos urbanísticos integrados, bem como define suas características, cria nova zona de uso e demais critérios. Segundo essa lei, plano urbanístico integrado referese ao parcelamento do solo, destinado à formação de núcleo diversificado de unidades habitacionais singulares ou coletivas, com previsão de áreas de comércio, serviço, entre outros. A lei permite também a formação e a implantação de núcleos residenciais fechados. Como núcleo residencial fechado, temos o parcelamento do solo urbano, caracterizado por ser um loteamento comum, onde as vias de circulação, as áreas livres e verdes internas poderão ser utilizadas com exclusividade pelos adquirentes dos lotes, através da concessão administrativa de uso, dada à associação, constituída pelos adquirentes, autorizando o seu fechamento e a utilização de vigilância exclusiva e particular.

Segundo uma técnica da Secretaria de Planejamento Municipal (Seplam), no que concerne à cidade de Goiânia,

[...] não temos uma legislação específica para condomínios fechados. Nós temos a Lei 4.526,

7. Conforme essa lei, considera-se como loteamento a subdivisão da gleba em lotes destinados à edificação, com abertura de novas vias de circulação, de logradouros públicos ou prolongamento, modificação ou ampliação das vias existentes.

8. Ainda em nível federal, temos a Lei $n^{\circ}$ 4.591, de dezembro de 1964, que dispõe sobre edificações em condomínios e as incorporações imobiliárias (Lei dos Condomínios). Em síntese, essa lei regulamenta sobre as edificações ou os conjuntos de edificações construídas na forma de unidade isolada, para fins residenciais ou não, e que constitui propriedade autônoma. Prevê, entre outros instrumentos jurídicos, a criação dos regimentos internos dos condomínios que estabelecem normas e condições de uso de cada unidade, para os fins que foram construídos. convencional e, dentro de um artigo dela, foi feita uma permissão para condomínio fechado. A gente tem dificuldades dentro da análise, com relação a questões como localização, áreas institucionais, devido a equipamentos e áreas verdes. [...] os equipamentos são colocados fora dos condomínios, para o atendimento da população do entorno, e as áreas verdes ficam lá dentro dos condomínios, as áreas de preservação obedecem a este critério. Agora, o fechamento ocorre realmente, com a concessão administrativa de uso, que é dada pra associação dos proprietários, dos compradores do terreno. Não é para a incorporadora que faz, essa associação forma-se e recebe a permissão, a concessão administrativa de uso. Com isso, é fechado. Você sabe que, em âmbito federal, lei que ordena condomínio fechado não existe? Agora é que me parece que estão querendo fazer alguma coisa, né! [...] então, geralmente os condomínios fechados são glebas grandes, e a gente olha mais ou menos assim, a questão do sistema viário da cidade, próximo a este espaço fechado, para não engessar e nós já temos certas regiões, onde já não são mais permitidas a implantação de condomínios fechados, por vários motivos, como por exemplo o limite do município e o possível engessamento. (Técnica da Seplam, em entrevista concedida em 8 de março de 2005)

São nesses termos e segundo essa legislação que a Prefeitura de Goiânia tem aberto concessão ao uso do solo urbano, para a implantação dos condomínios horizontais fechados.

É na metade da década de 1990 que percebemos o surgimento dos condomínios horizontais fechados em Goiânia. Em alguns bairros como o Jardim América, verificava-se a existência de pequenos condomínios, além da existência do próprio Privê Atlântico. No entanto, os complexos maiores, com todas as características próprias dos condomínios mais atuais, só começaram de fato a serem divulgados e implantados de 1994 para cá. Uma reportagem de $O$ Popular, jornal de maior circulação do estado, do ano de 1994, já dava indícios da oferta desse tipo de modalidade habitacional no espaço da cidade.

Viver com qualidade. Há muito tempo esse desejo vem habitando os sonhos de milhões de brasileiros. Certamente ao lado dele, a vontade de ganhar algumas vezes na loteria - 
Mapa 1 - Condomínios horizontais fechados da Região Metropolitana de Goiânia

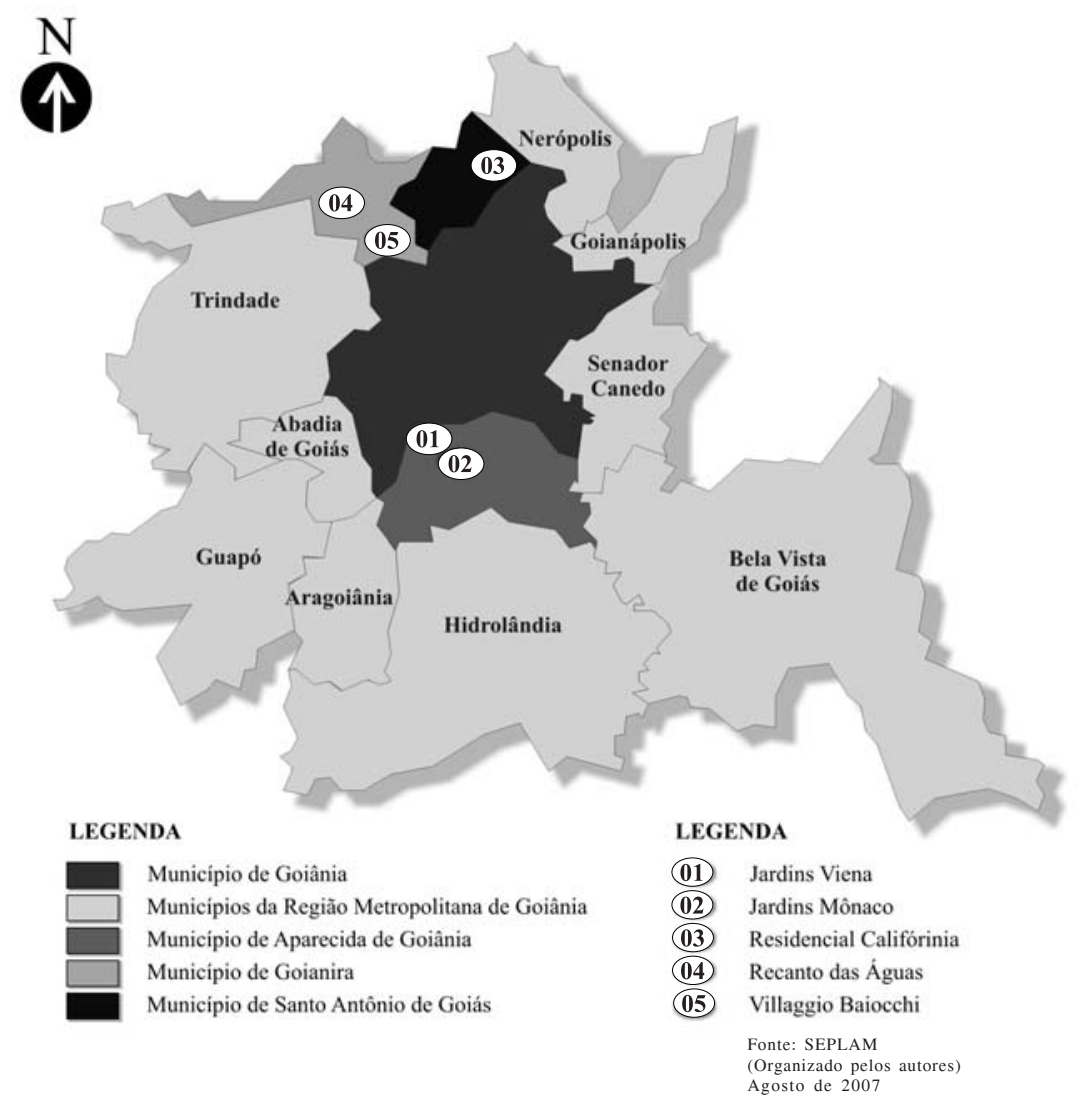

uma "mãozinha" de Deus! -, de ver o Brasil campeão e a URV de Fernando Henrique dar certo, pelo menos, nos seus sofridos bolsos. De todos esses sonhos mais que justos, um já é possível. E está bem ao alcance dos goianos. Qualidade de vida é sinônimo de conforto, comodidade, liberdade e segurança. De morar bem. Hoje, tudo isso é diretamente proporcional ao que chamamos de "condomínios horizontais", verdadeiras réplicas da casa-de-campo de nossos sonhos, só que dentro da cidade. (O Popular, 24 abr. 1994, p. 16)

Essa tendência mundial chegava à Goiânia, estando ao alcance de uma parcela da população da cidade. "Longe da poluição sonora e ambiental dos centros urbanos, os condomínios horizontais surgem como um achado, principalmente para os habitantes do Centro-Oeste, a maioria com raízes no interior e que preferem viver mais próximos ao chão, do que nas alturas de um condomínio vertical" (O Popular, 29 de abril de 1995, p. 13).

A busca por maior qualidade de vida, segurança e status social, pelas famílias de maior poder aquisitivo da população de Goiânia, ativou um mercado promissor. O sucesso do Jardins Viena (Região Sudoeste) levou o mercado imobiliário a lançar inúmeros outros projetos nos anos posteriores, com investimentos da ordem de R \$ 500 milhões em diversos outros lançamentos. Empreendimentos como Aldeia do Vale, Residencial Granville, Alphaville Flamboyant (primeira etapa) e Portal do Sol juntos somaram cifras da ordem de $\mathrm{R} \$ 209$ milhões.

Com a consolidação dos condomínios horizontais fechados como uma alternativa de moradia para a classe média e média alta da cidade, o mercado imobiliário acena hoje com modelos mais acessíveis, para bolsos não tão afortunados. A metrópole goiana apresenta, nos últimos anos, uma paisagem profundamente demarcada por essa tipologia, em um total de 19 condomínios. Somam-se a esses mais cinco outros, localizados em municípios vizinhos, que integram sua região metropolitana.

Como unidades residenciais segregadas, os condomínios fechados tocam em algumas ques- 
Mapa 2 - Condomínios horizontais fechados da cidade de Goiânia

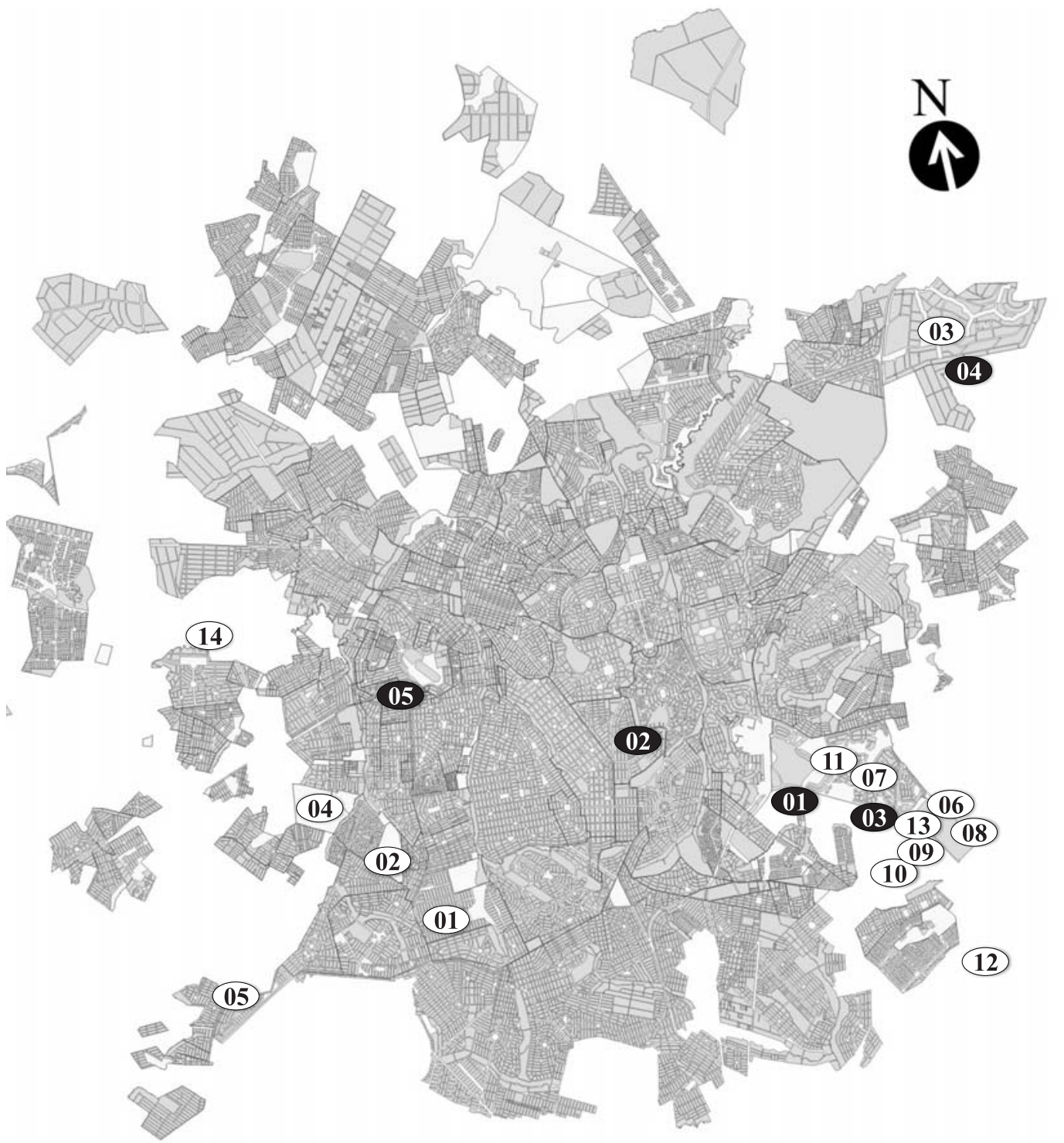

LEGENDA:

Condomínios horizontais fechados:

(01) Privê Atlântico (1978)

(02) Jardins Florença (1997)

03 Aldeia do Vale (1997)

(04) Residencial Granville (1998)

(05) Jardins Madri (2000)

(06) Portal do Sol I (2001)

(07) Complexo Alphaville Flamboyant (2001)

(08) Portal do Sol II (2002)

(09) Jardins Paris (2003)

(10) Jardins Atenas (2003)

11 Residencial Araguaia (2004)

12 Goiânia Golfe Residence (2005)

13 Jardins Milão (2005)

14 Condomínio do Lago (2005)

\section{Condomínios residenciais seriados:}

(01) Privê dos Girassóis (1999)

(02) Fontana Di Trevi (2001)

03 Housing Alphaville Flamboyant (2001)

04 Residencial Monte Verde (2001)

05 Condomínio Alto da Boa Vista (2004)
Fonte: COMDATA/SEPLAM (Organizado pelos autores) Agosto de 2007. 
tões importantes da vida urbana na cidade. $\mathrm{O}$ caráter segregacionista, evidenciado por seu espaço, torna-se forte agente na determinação e na reprodução de critérios, quanto a quem pode circular ou estar naquele local, mexendo de certa forma na questão da cidadania (Roberts, 2002).

Os altos muros estabelecem rupturas drásticas na paisagem urbana, que conformam dois campos distintos: privado e público, evidenciando ainda processos mais intensos de reprodução de desigualdades sociais. A Grande Goiânia demonstra uma opção crescente pela segregação física e pela estética dos muros, restringindo o acesso de estranhos às suas ruas internas. A apartação (Buarque, 1993) aqui é representada pela configuração de um espaço público em privatização. Os condomínios, em sua maioria, encontram-se nos subúrbios da cidade, compartilhando o espaço da periferia com a população pobre e evidenciando uma reprodução social perversa do espaço urbano.

Nos dias de hoje, as intensas atividades urbanas, principalmente no setor habitacional, têm propiciado uma extensão do espaço público em direção ao espaço privado e vice-versa. ${ }^{9}$ Mesmo que esse acesso ao uso público do espaço privado muitas vezes seja temporário, assistido ou monitorado, ele ocorre em grande escala e é reflexo de uma explosão das atividades oriundas de mudanças estruturais das profissões, principalmente no setor de serviços, comércio e planejamento.

Por outro lado, a rua, ou conjunto de ruas "O Bairro" -, que se caracteriza por ser um espaço genuinamente público, sem fechamento e que não necessita de identificação para circulação de público, veículos e algumas espécies de animais, encontra-se hoje sendo "privatizada". Fatos registram uma nova era, novos conceitos quanto ao modo de vida das pessoas, quanto ao poder e a abrangência do capital. ${ }^{10}$

Assim como os condomínios horizontais são exemplos de privatização de ruas, os edifícios de

9. Para maiores informações sobre as transformações do espaço público e da vida urbana moderna, consultar: Sennet (1988), Harvey (1992), Davis (1993), Caldeira (2000) e Jacobs (2000).

10. Essa tendência, por mais que venha revestida de uma certa modernidade, reforça hábitos tradicionais entre nós, caracterizando uma cultura patrimonialista brasileira. empresas de caráter privado acabam assumindo uma função pública. É o caso dos shopping centers. As pessoas transitam com toda facilidade por esses locais, entram e saem quando querem, sem ter de se identificar, mas estão constantemente na mira dos seguranças, das câmeras, sujeitas a um sistema montado para esse tipo de ambiente.

Pode-se compreender, portanto, que essa ampliação do espaço "público" dentro do espaço "privado" é mais uma forma de atrair e de alimentar o sistema capitalista, gerando lucros em prol da acumulação do capital e vice-versa. Compreende-se ainda que o poder do capital se mostre ainda mais audaz, à medida que subtrai espaço público da cidade, transformando-o em "quartéis de segurança" diante de uma sociedade "perigosa". Por outro lado, mas dizendo respeito ao mesmo processo, presenciamos a expansão de inúmeros espaços privados, como é o caso dos condomínios horizontais fechados.

Em um recente estudo, Macedo (2002) buscou um dimensionamento de tal realidade, enfocando a tendência de privatização dos espaços públicos em Goiânia. $\mathrm{O}$ autor procurou verificar em que medida os condomínios fechados desqualificam o espaço da cidade, indicando a emergência de um processo de valorização dos espaços privados em detrimento dos espaços públicos. Sua hipótese é confirmada ao mostrar que essa tipologia habitacional lança tendência no que tange a uma forma particular de vivenciar o espaço público da capital goiana, privilegiando espaços privados ou semipúblicos (condomínios horizontais fechados, shopping centers etc.) como locais próprios para a realização de interações diversas. No entanto, o próprio autor ressalta que tal questão não pode ser considerada de forma conclusiva, uma vez que essa é uma realidade ainda não muito cristalizada em Goiânia, destacando dessa forma o caráter exploratório de seu estudo. Este finaliza de forma interessante, ao questionar a futura geração que de fato está sendo gestada nesses espaços.

Internamente, o condomínio vai figurar como espaço de novas sociabilidades. Silva (2003), estudando esse fenômeno, a partir de um caso específico na cidade de Goiânia, o Privê Atlântico, visualiza uma nova cultura de morar, 
gestada por grupos específicos, grupos estes que apresentam um estilo de vida próprio, podendo denotar aqui um habitus, nos termos de Bourdieu. A referência à teoria de Bourdieu (1996 e 2001) se torna interessante, uma vez que Silva também vai entender o espaço físico como espaço social e daí perceber a formação de um habitus particular no espaço do condomínio. No entanto, parece-nos que aquilo que figurou como proposta acabou não sendo efetivado - os dados apresentados se mostraram insuficientes na confirmação da existência desse habitus, não podendo ser dimensionadas as implicações deste na vida urbana de Goiânia.

O que percebemos é que os condomínios têm figurado como pólo de atração de serviços, contribuindo para o processo de desconcentração, intensificando dessa forma a polinucleação da cidade, como nos ajuda a entender a teoria da produção social do espaço, de Gottdiener (1993). Embora Goiânia, tradicionalmente, tenha tido uma centralidade muito forte. $\mathrm{O}$ que percebemos, no entanto, é que o processo de polinucleação, em Goiânia, intensifica-se a partir da metade de 1980 e se estende até recentemente. A criação de novos lugares, com a construção dos condomínios fechados, tem provocado um aumento da população e de atividades comerciais e sociais nessas áreas. Essas mudanças são percebidas e sentidas por moradores do entorno; seus relatos nos dão uma idéia de como eles estão sentido tais alterações.

[...] Ah, se houve alterações! Com certeza, [...] eu moro nesta região há mais de 13 anos. Eu não sou daqui não, eu nasci em Palmeiras de Goiás, mas aí você sabe né? Cidade pequena [...], sem oportunidades [...], a gente acabou mudando pra cá, veio toda a minha família, logo que a gente veio, fomos morar no Novo Mundo, perto do Água Branca, não sei se você conhece, ali na Rua Tabatinga, pertinho da Av. Olinda. Meus pais ainda tão lá. Depois que eu casei, comprei esse lote aqui, no Jardim Brasil, foi o que a gente conseguiu comprar né? Fizemos esse barracão, mas com planos de construir uma casa maior aqui na frente. [...]. Quando eu e minha mulher mudamos pra cá, não tinha nada aqui no bairro, até pra gente ir trabalhar era complicado, transporte você sabe como é que é aqui em Goiânia né? Pegar ônibus é muito difícil, mais no meu caso eu nem tô falando de ônibus, porque eu tenho uma moto e trabalho lá no Jardim Bela Vista, numa oficina de lanternagem, perto do HDT. Antes, pra ir pra lá, eu gastava um tempão, o bairro aqui não tinha saída. Agora, com o condomínio aqui do lado, a gente tem outra ligação, pra ir pro serviço mesmo, eu acho melhor ir aqui por dentro do Alphaville, porque eu já saio lá na frente, sem ter que voltar na Av. Olinda todinha e passar pela BR, que é triste pra motoqueiro [...]. (Entrevista concedida em 9 de abril de 2005)

É interessante verificar, no depoimento transcrito, como o morador aponta algumas alterações na região, em função da instalação dos condomínios horizontais fechados. Para a maioria dos moradores dos bairros do entorno, algumas melhorias são visíveis, interferindo na qualidade de vida daquelas pessoas. Algumas benfeitorias de infra-estrutura são constantemente ressaltadas, entre outras.

[...] valorização da área, a expansão da cidade e a vinda de novos moradores pra esta região. Na questão comercial foi maravilhoso, valorizou a área, essa área tá expandindo muito né? Aí, aqui passou a ser mais conhecido, antes ninguém sabia onde ficava o Parque Atheneu, e muito menos o Mariliza, hoje mudou tem até melhor linha de ônibus. (Morador do Jardim Mariliza, próximo aos Jardins; entrevista concedida em 16 de abril de 2005).

[...] houve melhoria sim, energia à noite, não tá tão perigoso como antes. Aqui era muito escuro, agora tá uma beleza, à noite fica até bonito. E depois tem também o emprego né.

[...] tudo tá muito diferente, houve melhoria sim [...], hoje já temos clientes moradores dos condomínios; [...] além da valorização, só pra você ter uma idéia, eu tenho um lote, aqui mais à frente, na Av. das Gameleiras, que há seis anos atrás eu coloquei à venda, por $\mathrm{R} \$ 40.000,00$, mas acabei não vendendo na época, hoje já recebi oferta de até $\mathrm{R} \$ 120.000,00$. (Proprietária de um estabelecimento comercial no Bairro Água Branca, situado na Av. Olinda; entrevista concedida em 9 de abril de 2005)

Estruturalmente, a Região Metropolitana de Goiânia, tem sofrido alterações bastante significativas com a implantação dos condomínios fechados. A malha urbana foi profundamente 
modificada para suportar a implantação de tais empreendimentos, houve a criação de um sistema viário exclusivo e de uso coletivo (avenidas, ruas e viaduto), que interliga regiões, antes separadas e modifica vias intermunicipais, alterando o cotidiano da região. Como exemplos dessa reestruturação na Região Metropolitana, temos a abertura da avenida, ligando os Jardins, até o Campus II da UCG e o viaduto Alphaville Flamboyant, feitos pelas incorporadoras dos condomínios, em parceria com a Prefeitura Municipal. Essas duas estruturas viárias possibilitaram uma integração com a malha urbana da região e da Grande Goiânia. Tais mudanças na infra-estrutura da Região Sudeste alteraram sensivelmente a área. Bairros que antes tinham apenas uma saída para as áreas mais centrais de Goiânia contam hoje com outras alternativas de deslocamento. O Parque Atheneu e o Jardim Mariliza, dois grandes bairros no entorno dos Jardins, passaram a ter, com as alterações, ligação com a GO-020 que, por sua vez, se liga à $\mathrm{BR}-153$, fazendo com que a população dos dois bairros e de outros próximos tenham acesso mais rápido à parte leste da capital.

Essa ação das incorporadoras (FGR Construtora, Flamboyant e Alphaville Urbanismo), em parceria com o poder público, dá-nos uma noção de como tem sido as relações entre esses dois atores nessa região. Percebemos que, apesar de as incorporadoras estarem à frente da implantação dos condomínios, o processo não acontece sem a presença do poder público, ainda que essa presença se dê mais em termos legais, no que se refere à aprovação e à fiscalização tanto dos projetos dos condomínios quanto dos projetos de alteração da infra-estrutura da área. Queremos ressaltar a força de ação do capital imobiliário à frente desse processo, redefinindo os limites e a expansão da cidade. A prefeitura, através da sua Secretaria de Planejamento, por mais que tente disciplinar o uso do solo na cidade, tentando fazer cumprir sua função social, vê-se impotente diante do capital, que acaba orientando o crescimento da cidade, de acordo com seus interesses. Percebemos que interesses convergentes entre capital e poder público muitas vezes são nocivos à cidade.

A discussão sobre expansão urbana é uma das mais problemáticas para a Seplam. O alar- gamento horizontal da cidade traz ônus e quem paga o preço disso é o conjunto da população. Quanto mais se aprovarem loteamentos distantes da malha urbana, mais caro custa levar os benefícios sociais, como eletricidade, água, esgoto, asfalto, transporte, escolas, segurança e lazer a esses novos bairros. Esta é uma discussão mais problemática ainda, por esbarrar na existência de inúmeros espaços centrais ainda vazios que poderiam abrigar edificações. Conforme vimos, os interesses da iniciativa privada é que dão o tom e a direção ao crescimento da cidade.

A implantação dos condomínios fechados tem atraído outros investimentos, ativando um círculo de crescimento, ainda incalculável. Houve uma valorização dos terrenos nos bairros do entorno. Os preços subiram, não só dos bairros fronteiriços aos condomínios, mas também dos outros bairros que compõem as regiões. Essa valorização é sentida por todos os entrevistados, moradores dos bairros do entorno, e ressaltada pelos agentes imobiliários.

Mensurar essa valorização em dados mais substanciais se torna uma tarefa complexa. Diante dessa lacuna, achamos interessante conferir a planta de valores, ${ }^{11}$ organizada pelo órgão de planejamento de Goiânia, já que ela poderia nos fornecer informações que nos mostrassem a evolução dos preços de setores próximos a condomínios fechados, antes e depois de suas implantações.

Para nossa análise, foram consultadas as plantas de valores imobiliários dos últimos dez anos. Porém, trabalhamos apenas com quatro plantas elaboradas pela Seplam: a de 1995, exercício de 1996; a de 1998, exercício de 1999; a de 2001, exercício de 2002, e a planta elaborada em 2003, exercício de 2004 (Tabela 1). Em alguns momentos, ao longo desse período, tais plantas foram complementadas e/ou atualizadas, com registro em portarias específicas.

\footnotetext{
11. A planta de valores imobiliários elaborada pela Secretaria Municipal de Planejamento determina o valor por $\mathrm{m}^{2}$ do terreno, que serve de base de cálculo do valor venal dos imóveis, a ser utilizado para o lançamento do Imposto sobre a Propriedade Predial e Territorial urbana (IPTU), do Imposto sobre a Transmissão "Inter Vivos" (ISTI), bem como a cessão de direitos a sua aquisição e também base de cálculo para a indenização dos imóveis desapropriados pelo município por interesse social.
} 
Tabela 1 - Planta de valores dos bairros da Região Sul

\begin{tabular}{|c|c|c|c|c|c|c|c|c|c|c|}
\hline Microrregião & Composição & 1996 & 1999 & MV\% & 1999 & 2002 & MV\% & 2002 & 2004 & MV\% \\
\hline \multirow[t]{8}{*}{ 58- Autódromo } & $\begin{array}{l}1 \text { - Autódromo Intern. de } \\
\text { Goiânia }\end{array}$ & 7,00 & 7,00 & 0,0 & 7,00 & 85,00 & 1114,3 & 85,00 & 94,29 & 10,9 \\
\hline & 2 - Jardim Goiás (parte) & 50,00 & 65,00 & 30,0 & 65,00 & 115,00 & 76,9 & 115,00 & 160,00 & 39,1 \\
\hline & 3 - Privê dos Girassois & - & - & - & - & 60,00 & - & 60,00 & 66,56 & 10,9 \\
\hline & 4 - Residencial Aruanã & - & - & - & - & 20,00 & - & 20,00 & 22,19 & 11,0 \\
\hline & 5 - Vila Jardim Vitória (parte) & 9,00 & 12,00 & 33,3 & 12,00 & 25,00 & 108,3 & 25,00 & 27,73 & 10,9 \\
\hline & 6 - Parque Lozandes & 7,00 & 10,00 & 42,9 & 10,00 & 100,00 & 900,0 & 100,00 & 110,93 & 10,9 \\
\hline & $\begin{array}{l}7 \text { - Parque Lozandes } \\
\text { (Área Inst.) }\end{array}$ & - & - & - & - & 80,00 & - & 80,00 & 88,74 & 10,9 \\
\hline & $\begin{array}{l}8 \text { - Parque Lozandes } \\
\text { (Área de Preserv.) }\end{array}$ & - & 4,80 & - & 4,80 & 49,00 & 920,8 & 49,00 & 51,00 & 4,1 \\
\hline \multirow{9}{*}{$\begin{array}{l}61-\text { Parque das } \\
\text { Laranjeiras }\end{array}$} & 1 - Campus II - UCG & - & 1,00 & - & 1,00 & 30,00 & 2900,0 & 30,00 & 33,28 & 10,9 \\
\hline & 2 - Chácara Alto da Glória & 5,80 & 7,00 & 20,7 & 7,00 & 16,20 & 131,4 & 16,20 & 17,50 & 8,0 \\
\hline & 3 - Chácara do Governador & 10,00 & 12,00 & 20,0 & 12,00 & 70,00 & 483,3 & 70,00 & 77,65 & 10,9 \\
\hline & 4 - Conjunto Anhanguera & 13,00 & 15,00 & 15,4 & 15,00 & 40,00 & 166,7 & 40,00 & 44,37 & 10,9 \\
\hline & 5 - Conjunto Fabiana & 12,00 & 18,00 & 50,0 & 18,00 & 40,00 & 122,2 & 40,00 & 44,37 & 10,9 \\
\hline & 6 - Jardim Bela Vista & 10,00 & 15,00 & 50,0 & 15,00 & 31,20 & 108,0 & 31,20 & 33,28 & 6,7 \\
\hline & 7 - Jardim da Luz (parte) & 15,00 & 18,00 & 20,0 & 18,00 & 40,00 & 122,2 & 40,00 & 44,37 & 10,9 \\
\hline & 8 - Jardim Mariliza & 7,00 & 11,00 & 57,1 & 11,00 & 30,00 & 172,7 & 30,00 & 33,28 & 10,9 \\
\hline & $\begin{array}{l}9 \text { - Jardim Santo Antônio } \\
\text { (parte) }\end{array}$ & 14,00 & 18,00 & 28,6 & 18,00 & 40,00 & 122,2 & 40,00 & 44,37 & 10,9 \\
\hline \multirow[t]{9}{*}{$\begin{array}{l}61-\text { Parque das } \\
\text { Laranjeiras }\end{array}$} & $\begin{array}{l}10 \text { - Parque Acalanto } \\
(\text { Conj. Carajás })\end{array}$ & 20,00 & 30,00 & 50,0 & 30,00 & 55,00 & 83,3 & 55,00 & 61,00 & 10,9 \\
\hline & 11 - Parque Atheneu & 9,00 & 14,00 & 55,6 & 14,00 & 30,00 & 114,3 & 30,00 & 33,28 & 10,9 \\
\hline & 12 - Parque das Laranjeiras & 20,00 & 24,00 & 20,0 & 24,00 & 45,00 & 87,5 & 45,00 & 49,92 & 10,9 \\
\hline & $\begin{array}{l}13 \text { - Parque Resd. } \\
\text { Flamboyant (Goiânia) }\end{array}$ & - & - & - & - & 15,00 & - & 15,00 & 16,64 & 10,9 \\
\hline & 14 - Parque Santa Cruz & 8,00 & 10,00 & 25,0 & 10,00 & 15,00 & 50,0 & 15,00 & 16,64 & 10,9 \\
\hline & $\begin{array}{l}15 \text { - Residencial Ville De } \\
\text { France }\end{array}$ & - & - & - & - & - & - & - & - & - \\
\hline & 16 - Jardim Vitória (parte) & - & - & - & - & - & - & - & - & - \\
\hline & 17 - Vila Legionárias & 8,00 & 12,00 & 50,0 & 12,00 & 25,00 & 108,3 & 25,00 & 27,73 & 10,9 \\
\hline & $\begin{array}{l}18 \text { - Vila Vicentina José de } \\
\text { Jesus }\end{array}$ & 8,00 & 10,00 & 25,0 & 10,00 & 18,00 & 80,0 & 18,00 & 19,20 & 6,7 \\
\hline $\begin{array}{l}\text { 77- Vila Alto } \\
\text { da Glória }\end{array}$ & 1 - Vila Alto da Glória & 7,00 & 8,00 & 14,3 & 8,00 & 16,00 & 100,0 & 16,00 & 17,10 & 6,9 \\
\hline $\begin{array}{l}\text { 78- Portal do } \\
\text { Sol }\end{array}$ & 1 - Lot. Portal do Sol I e II & - & - & - & - & 60,00 & - & 60,00 & 68,90 & 14,8 \\
\hline $\begin{array}{l}\text { 79- Alphaville } \\
\text { Flamboyant }\end{array}$ & $\begin{array}{l}1 \text { - Lot. Alphaville } \\
\text { Flamboyant }\end{array}$ & - & - & - & - & 135,00 & - & 135,00 & 149,76 & 10,9 \\
\hline 80- Jardins & 1 - Lot. Jardins & - & - & - & - & - & - & - & - & - \\
\hline
\end{tabular}

Fonte: Seplam (dados organizados pelos autores) 
Observamos, mediante a análise dos dados da tabela da Região Sudeste de Goiânia, que houve um aumento dos preços dos terrenos no período entre 1999 e 2002. Esse aumento evidencia uma valorização ascendente, com certa expressividade. Fica evidente na análise dos dados desta tabela que principalmente a microrregião Autódromo, entre os anos de 1999 e 2002 (período de implantação dos principais condomínios), teve o valor dos terrenos aumentado substancialmente. Os índices dessa valorização só são comparáveis ao mesmo período de implantação de outros equipamentos no bairro, como o Shopping Flamboyant, na década de 1980, que constituiu um pólo de atração de novos empreendimentos, como edifícios de apartamentos, para o entorno próximo.

Ao comparar os principais bairros do entorno e próximos aos condomínios da Região Sudeste de Goiânia - Alphaville, Portal do Sol, Privê dos Girassóis e Jardins -, temos uma idéia mais clara desse processo de valorização, já analisado anteriormente (ver Tabela 2).

O Gráfico 1 reforça os índices de valorização dos bairros do entorno, nos períodos de 1999 a 2002 , em que verificamos um aumento nos preços dos terrenos em todos essas localidades.

Sabemos que não podemos isolar os condomínios, apresentando-os como único elemento de impacto no processo de valorização dos

Tabela 2 - Valorização dos principais bairros do entorno dos condomínios horizontais fechados da Região Sudeste

\begin{tabular}{|l|l|l|c|c|c|}
\hline Região & Microrregião & Composição & $\mathbf{1 9 9 6 - 1 9 9 9}$ & $\mathbf{1 9 9 9 - 2 0 0 2}$ & $\mathbf{2 0 0 2 - 2 0 0 4}$ \\
\hline \multirow{2}{*}{ Sul } & $54-$ Jardim Goiás & $\begin{array}{l}\text { Jardim Goiás (Área do } \\
\text { Comp. Flamb.) }\end{array}$ & $20,0 \%$ & $83,3 \%$ & $10,9 \%$ \\
\hline \multirow{3}{*}{ Leste } & $56-$ Água Branca & Bairro Água Branca & $20,0 \%$ & $122,2 \%$ & $10,9 \%$ \\
\cline { 2 - 6 } & $57-$ Riviera & Jardim Brasil & $33,3 \%$ & $150,0 \%$ & $10,9 \%$ \\
\hline \multirow{3}{*}{ Sudeste } & $58-$ Autódromo & Jardim Goiás (parte) & $30,0 \%$ & $76,9 \%$ & $39,1 \%$ \\
\cline { 2 - 6 } & \multirow{2}{*}{$61-$ Parque das Laranjeiras } & Jardim Mariliza & $57,1 \%$ & $172,7 \%$ & $10,9 \%$ \\
\cline { 2 - 6 } & & Parque das Laranjeiras & $20,0 \%$ & $87,5 \%$ & $10,9 \%$ \\
\cline { 2 - 6 } & & Parque Atheneu & $55,6 \%$ & $114,3 \%$ & $10,9 \%$ \\
\hline
\end{tabular}

Fonte: Seplam (dados organizados pelos autores)

Gráfico 1 - Valorização dos principais bairros do entorno dos condomínios horizontais fechados da Região Sudeste

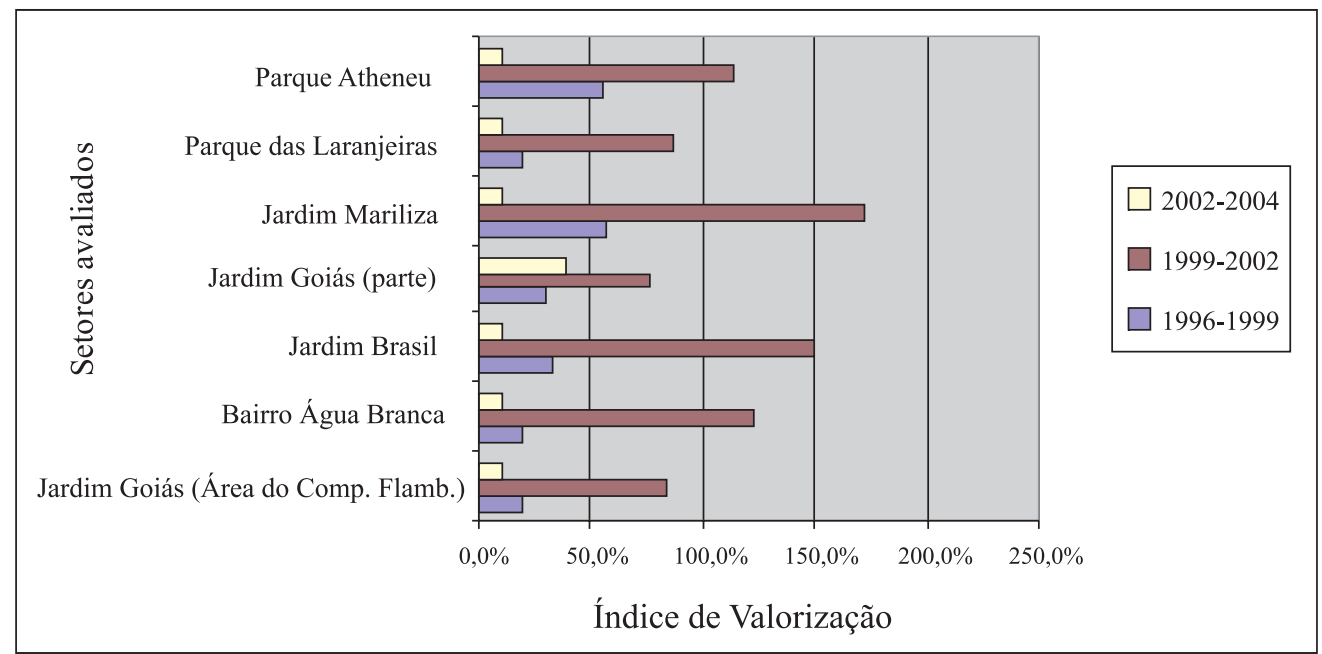

Fonte: Seplam (Dados organizados pelos autores) 
terrenos dos bairros do entorno, ${ }^{12}$ mas verificamos uma relação direta entre valorização e implantação dos condomínios, mexendo em toda a estrutura daquela área, fato confirmado quando comparamos os índices de valorização desses bairros com outros, de características semelhantes, em outras regiões da cidade e que não se encontram sob a influência de condomínios fechados. Para confirmação desses dados, foram confrontados os índices de valorização de alguns desses bairros com outros bairros da cidade, que apresentavam alguns elementos comuns, como período de criação, classe, destino e ocupação (Tabela 3).

No geral, esses bairros apresentam algumas semelhanças, como período de implantação, características estruturais e composição social. No entanto, demonstram processos distintos de valorização, com índices mais acentuados para os circunvizinhos a condomínios (ex: Parque Atheneu).
É importante pontuar que a planta de valores indica o valor venal do terreno, podendo ou não coincidir com o de mercado. Se fôssemos analisar os valores indicados pelo mercado, com certeza, essa projeção de valorização se mostraria maior. Outra questão importante a ser ressaltada é que nossa compreensão não se dá a partir de uma análise causal, na qual o condomínio estaria determinando diretamente o aumento dos preços dos terrenos nos bairros próximos. O condomínio não constitui o elemento determinador dessa valorização. Consideramos, no entanto, que ele figura como elemento dessa composição, sendo hoje o mais importante.

Tendo os condomínios fechados como elemento importante na reestruturação da Região Metropolitana de Goiânia, vamos verificar uma valorização, com a constatação de preços mais elevados não só em lotes vazios, mas também em espaços edificados, ocupados ou não. $\mathrm{O}$ próprio marketing urbano em cima dos condo-

Tabela 3 - Quadro comparativo entre bairros (Parque Atheneu e Vila Canaã)

\begin{tabular}{|l|l|l|c|c|c|}
\hline Região & Microrregião & Composição & $\mathbf{1 9 9 6 - 1 9 9 9}$ & $\mathbf{1 9 9 9 - 2 0 0 2}$ & $\mathbf{2 0 0 2 - 2 0 0 4}$ \\
\hline Sudeste & 61- Parque das Laranjeiras & Parque Atheneu & $55,6 \%$ & $114,3 \%$ & $10,9 \%$ \\
\hline Sudoeste & 17 - Jardim Europa & Vila Canaã & $16,7 \%$ & $19,0 \%$ & $12,0 \%$ \\
\hline
\end{tabular}

Fonte: Seplam (dados organizados pelos autores)

Gráfico 2 - Comparativo entre bairros (Parque Atheneu e Vila Canaã)

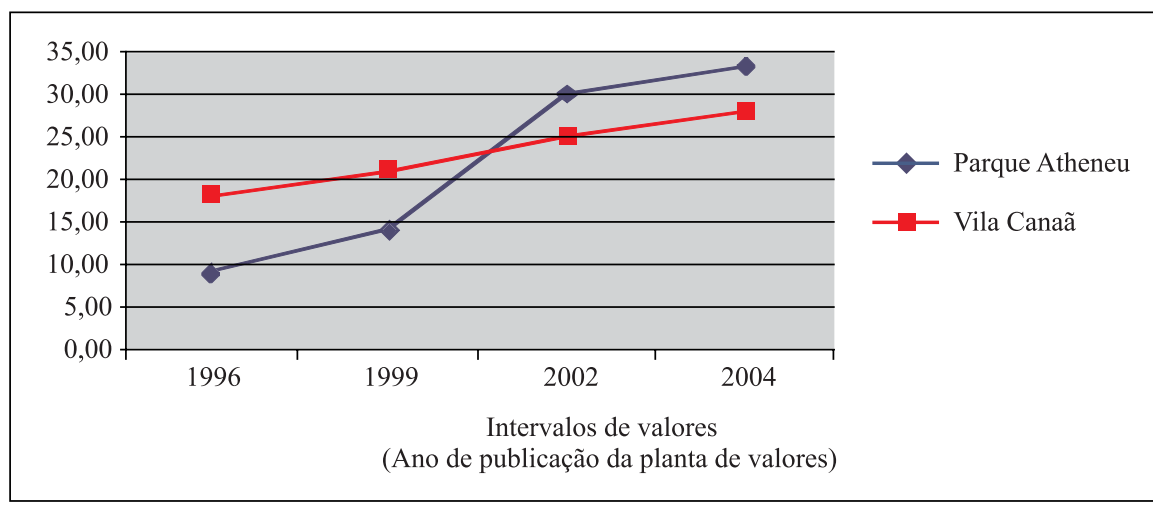

Fonte: Seplam (Dados organizados pelos autores)

12. Temos visto na imprensa um marketing imobiliário muito grande, voltado para a Região Sudeste. A ação das imobiliárias, com base nas propagandas, tem direcionado e ativado uma valorização grande da área. Inclusive parte das propagandas é divulgada tendo os condomínios como coadjuvantes na venda de outros empreendimentos. A área é comercializada a partir do atrativo dos condomínios fechados. 
mínios acaba gerando expectativas que, sem sombra de dúvida, influenciam nos preços.

O que observamos é que a implantação e a manutenção dos condomínios dependem da criação de toda uma estrutura, o que gera, por exemplo, empregos de prestadores de serviço e a atração de novos comércios. Os serviços de segurança, principalmente externos, oferecem uma sensação de segurança para os moradores do entorno. Esses fatores todos produzem um aumento do valor do solo, valorizando a região.

Mas o que percebemos é que as mudanças não são somente físicas e espaciais, são também sociais. Notadamente tais espaços representam uma mudança no padrão residencial urbano, acenando para a gestação de uma nova cultura de morar na cidade. Diferentes classes passam a viver mais próximas, mas mantidas separadas por barreiras físicas, como os altos muros dos condomínios (Caldeira, 2000).

A produção de espaços exclusivos, na Grande Goiânia, é recente ${ }^{13}$ e atrela-se a uma tendência de perda funcional dos espaços públicos. Isso, sem dúvida, fomenta uma cultura de autosegregação, informando práticas distintas de habitar e morar na cidade. O movimento da classe média-alta goiana, para as franjas da cidade, significa muito mais do que um simples deslocamento espacial, mas indica a formação de um habitus, no sentido verdadeiramente bourdiano, condicionado a valores como (auto) segregação, segurança, exclusividade e qualidade de vida.

A busca por segurança, qualidade de vida e status é o aspecto fundante do que estamos chamando de um habitus, no contexto da Grande Goiânia. Esse habitus é ele mesmo um conjunto verbal, discursivo e de práticas, representando formas novas de apropriação do espaço urbano, com implicações e reflexos ainda de difícil dimensionamento.

Sabemos que nem sempre ocupar fisicamente um lugar implica necessariamente habitálo, no entanto, observamos a importância do espaço físico do condomínio fechado como lugar da moradia, espaço percebido e base de percepção da realidade. Foi essa observação que nos

13. Entendemos aqui como recente a implantação dos condomínios horizontais fechados nos modelos atuais. indicou a formação de uma cultura diferenciada. Sendo assim, talvez o aldeão, o alphavilense, o jardinense ou o granvilense ${ }^{14}$ sejam os metropolitanos típicos, aquele cosmopolita bemsucedido que quer estar na cidade sem vivenciar a complexidade urbana dela.

Assim, acreditamos que as mudanças no espaço da Região Metropolitana de Goiânia, que não são somente físicas, mas também sociais, vinculam-se a uma mudança no padrão residencial urbano, acenando para a gestação de uma nova cultura de morar na cidade.

O estudo reflete sobre a localização territorial como reprodutora das desigualdades sociais interclasses na metrópole (Ribeiro, 2004). Locus onde "iguais" estão próximos de "diferentes" (as áreas periféricas desprovidas de equipamentos de infra-estrutura passam a ter uma outra conotação, seja ela imobiliária ou de serviço valorizado). Como também, em função da consolidação dessa nova tipologia residencial, é gestado um novo tipo de vivência social composta por habitus (Bourdieu,1996) e cultura de grupos distintos.

Parece evidente que essa nova maneira de habitar a cidade, tolerada pelo poder público, constitui uma solução menos democrática, na medida em que segrega em vez de unir, desobrigando o Estado do cumprimento de deveres para com a população. O estágio alcançado por essa nova forma de "viver na cidade" é resultado de um processo de mão dupla: de um lado, o setor imobiliário que se aproveita da situação em que se encontra a sociedade e cria nichos de mercados seletivos para os possuidores de alta renda; estes, por sua vez, para fugir da cidade caótica em termos de violência e para buscar privacidade, procuram refúgios mais seguros, com medo de criminosos e marginais. Essas várias modalidades de habitar interferem nas formas urbanísticas da cidade, no desenho arquitetônico e nas dimensões sociopolíticas, no que tange ao direito à cidade, como processo coletivo de apropriação desigual, ocasionando a privatização do espaço público, da segurança e da infra-estrutura básica e, conseqüentemente, os processos de isolamento e uma aparente

14. Para nos referirmos aos moradores do Aldeia do Vale, Alphaville Flamboyant, Jardins e Granville. 
"autonomização" com relação à cidade (Bernardes, Moysés, 2006).

A insegurança e o medo da violência criam novos códigos arquitetônicos. Emerge, dessa forma, a "cultura pública do medo", comentada por Bauman (2003), que se efetiva em um processo de mercadorização das formas que garantem a segurança não apenas por intervenções a posteriori. Empresas, edifícios residenciais, habitações isoladas ou na forma condominial são projetados tendo como referência projetos modernos de segurança. Esse movimento constitui uma nova forma de ocupar a cidade, marcado, por um lado, pela fuga das habitações verticalizadas e, por outro, pela privatização do espaço público. É claro que a preocupação com a segurança por vezes encerra um elemento que vai além do cálculo objetivo do risco.

\footnotetext{
Abstract: This paper focus the impacts that have been caused by closed horizontal condominiums into Metropolitan of Goiânia. The new sort of housing shows itself as a new way of urban social and space segregation, an increasing social process were great parcels of the population have moved to those closed districts, surrounded by huge walls and sophisticated security systems. The housing sector has always played an important role the crowding and urban development of this area, this process has demonstrated new features since the introduction of closed horizontal condominiums, contributing to the development of a new Goiânia intrametropolitan space.
}

Key-words: closed horizontal condominiums; Metropolitan Region of Goiânia; social and space reorganization; urban design; extension centers.

\section{Referências}

ALMADA, M. Condomínios fechados saúdam o povo e exigem passagem. Revista Projeto (Revista Brasileira de Arquitetura, Planejamento, Desenho industrial e Construção), n 51,1998 , p. 40.

ALMEIDA, R. A. Olhando a cidade atrás dos muros: um estudo de caso do condomínio horizontal fechado Aldeia do Vale. Goiânia, 2004. Dissertação (Mestrado em Geografia) - Instituto de Estudos Sócio-ambientais, Universidade Federal de Goiás.

ANDRADE, L. Segregação sócio espacial e vida cotidiana: o caso dos condomínios fechados. Anpocs. 2002.
BAUMAN, Z. Comunidade: a busca por segurança no mundo atual. Rio de Janeiro, Zahar Editor, 2003. BERNARDES, D.; MOYSÉS, A. Segregação urbana e desigualdade social: estado e mercado imobiliário. Goiânia: Editora da UCG, 2001. p. 173-205.

BOURDIEU, P. et. al. Efeito de lugar. In: BOURDIEU, et. al. A miséria do mundo. Petrópolis, Rio de Janeiro: Vozes, 2001.

. Espaço social e espaço simbólico. In: Razões práticas: sobre a teoria da ação. Campinas-SP, 1996. p. 13-34.

BUARQUE, C. O que é apartação - o apartheid social no Brasil. São Paulo: Brasiliense, 1993.

CALDEIRA, M. T. P. do R. Cidade de muros: crime, segregação e cidadania em São Paulo. São Paulo: Ed. 34/Edusp, 2000.

CASTELLS, M. Mudanças tecnológicas, reestruturação econômica e a nova divisão espacial do trabalho. Espaço e Debate, ano VI, n. 17, São Paulo: Nobel, 1992. p. 5-23.

DAVIS, M. Cidade de quartzo - escavando o futuro em Los Angeles. São Paulo: Ed. Página Aberta Ltda., 1993.

GOTTDIENER, M. A produção do espaço urbano. São Paulo: Edusp, 1993. p. 11-34.

HARVEY, D. Condição pós-moderna. São Paulo: Ed. Loyola, 1992.

INSTITUTO BRASILEIRO DE GEOGRAFIA E ESTATÍSTICA. Censo demográfico. Disponível em: <www.ibge.gov.br/home/estatística/populaçao/ censo 2000>. Acesso em: 12/8/2007.

JACOBS, J. Morte e vida das grandes cidades. São Paulo: Martins Fontes, 2000.

JAMESON, F. Pós-modernismo: a lógica cultural do capitalismo tardio. São Paulo: Ática, 1997.

LAGO, L. C. Estruturação urbana e mobilidade espacial: uma análise das desigualdades socioespaciais na metrópole do Rio de Janeiro. São Paulo, 1998. Tese (Doutorado em Estruturas Ambientais Urbanas) - Faculdade de Arquitetura e Urbanismo, Universidade de São Paulo.

LEVY, E. Democracia nas cidades globais. São Paulo: Nobel, 1997.

MACEDO, J. E. R. Condôminos horizontais fechados: desqualificadores do espaço público? O caso de Goiânia. Goiânia, 2002. Dissertação (Mestrado em Sociologia) - Faculdade de Ciências Humanas e Filosofia, Universidade Federal de Goiás.

O POPULAR. Condomínios: qualidade de vida e segurança para o lar. Goiânia, 24 abr. 1994, p. 16. 
Segurança é o forte do condomínio horizontal. Goiânia, 29 abr. 1995, p. 13.

RIBEIRO, L. C. de Q. (Org.) Metrópoles: entre a coesão e a fragmentação, a cooperação e conflito. São Paulo: Ed. Fundação Perseu Abramo; Rio de Janeiro: Fase, 2004.

ROBERTS, A. M. S. Cidadania interditada: um estudo de condomínios horizontais fechados São Carlos, 2002. Tese (Doutorado em Sociologia) Instituto de Ciências Humanas e Filosofia, Universidade Estadual de Campinas.

SASSEN, S. As cidades na economia mundial. São Paulo, Nobel, 1998.

SENNET, R. O declínio do homem público: as tiranias da intimidade. São Paulo: Cia. das Letras, 1998.

SILVA, R. F. da. Condomínios horizontais fechados em Goiânia - Um caso: Privê Atlântico. Goiânia,
2003. Dissertação (Mestrado em Sociologia) Faculdade de Ciências Humanas e Filosofia, Universidade Federal de Goiás.

SOARES J. A. A. Condôminos horizontais fechados e a configuração de um novo espaço intrametropolitano de Goiânia. Goiânia, 2005. Dissertação (Mestrado em Sociologia) - Faculdade de Ciências Humanas e Filosofia, Universidade Federal de Goiás. TRAMONTANO, M. P.; REGINALDO, L. Habitação contemporânea na cidade de São Paulo: evolução recente de algumas tipologias. São Carlos, SP: Ghab, 1999.

TOURAINE, A. Crítica à modernidade. Petrópolis: Vozes, 1994.

WACQUANT, L. Os condenados da cidade. [S. 1.]: Revan/Fase, 2001. 
